\title{
Henry's voices: the representation of auditory verbal hallucinations in an autobiographical narrative
}

\author{
Zsófia Demjén, ${ }^{1}$ Elena Semino
}

${ }^{1}$ Department of Applied Linguistics and English Language, The Open University, Milton Keynes, UK ${ }^{2}$ Department of Linguistics and English Language, Lancaster University, Lancaster, UK

\section{Correspondence to}

Dr Zsófia Demjén, Department of Applied Linguistics and English Language, The Open University, FELS, Stuart Hall, Level 2, Milton Keynes MK7 6AA, UK;

zsofia.demjen@open.ac.uk

Accepted 24 November 2014 Published Online First

11 December 2014

\section{CrossMark}

To cite: Demjén $Z$ Semino E. Med Humanit 2015;41:57-62.

\section{ABSTRACT}

The book Henry's Demons (2011) recounts the events surrounding Henry Cockburn's diagnosis of schizophrenia from the alternating perspectives of Henry himself and his father Patrick. In this paper, we present a detailed linguistic analysis of Henry's first-person accounts of experiences that could be described as auditory verbal hallucinations. We first provide a typology of Henry's voices, taking into account who or what is presented as speaking, what kinds of utterances they produce and any salient stylistic features of these utterances. We then discuss the linguistically distinctive ways in which Henry represents these voices in his narrative. We focus on the use of Direct Speech as opposed to other forms of speech presentation, the use of the sensory verbs hear and feel and the use of 'non-factive' expressions such as / thought and as if. We show how different linguistic representations may suggest phenomenological differences between the experience of hallucinatory voices and the perception of voices that other people can also hear. We, therefore, propose that linguistic analysis is ideally placed to provide in-depth accounts of the phenomenology of voice hearing and point out the implications of this approach for clinical practice and mental healthcare.

\section{INTRODUCTION}

In this paper, we investigate, from a linguistic perspective, how 'auditory verbal hallucinations' (AVHs) are represented in the autobiographical narrative, Henry's Demons: Living with Schizophrenia, A Father and Son's Story. ${ }^{1}$ Henry Cockburn was diagnosed with schizophrenia in 2002, at the age of 20 years. During his recovery in 2008, Henry and his father, the journalist Patrick Cockburn, began to write their 'story of living with schizophrenia' and in 2011 their coauthored book, Henry's Demons (HD), was published. We focus on the five and a half chapters in HD written by Henry and consider the ways in which he writes about his experiences of voices that one might call hallucinatory. We treat Henry as a 'voice-hearer" for whom AVHs constitute meaningful and important experiences and as an 'expert by experience', ${ }^{3}$ that is, as speaking with authority about voicehearing as a result of his first-hand knowledge of what his voices feel like. To account for how Henry conveys the richness and complexity of his voicehearing experiences, we provide a typology of the voices he reports and show the linguistically distinctive ways in which he represents them in his narrative. We reflect on the implications of these features for Henry's individual experience of voicehearing. We propose that linguistic analysis is ideally placed to account for how patients such as
Henry describe the personal experiences that have led to a psychiatric diagnosis ${ }^{4}$ and suggest that this approach may, therefore, be relevant to clinical practice and mental healthcare.

A hallucination can be defined as:

[a] sensory experience which occurs in the absence of corresponding external stimulation of the relevant sensory organ, has a sufficient sense of reality to resemble a veridical perception, over which the subject does not feel $\mathrm{s} / \mathrm{he}$ has direct and voluntary control and which occurs in the awake state. ${ }^{5}$

Our object of study, AVHs, or 'voice-hearing', is a subtype of the more general phenomenon and tends to be described as being both auditory and verbal in nature. Although voice-hearing is not necessarily a symptom of a psychiatric disorder (see below), ${ }^{6}$ persistent AVHs can, in some cases on their own, lead to a schizophrenia diagnosis. ${ }^{7}$ It is, therefore, important that as much as possible is understood about them and their phenomenological features. ${ }^{8}$ Investigating Henry's representation of voices through a linguistic lens allows us to arrive at observations and phenomenological insights that are, to the best of our knowledge, undocumented in the clinical literature on schizophrenia.

After presenting a background to HD and the literature on AVHs, we begin our analysis with a typology of voices, taking into account who speaks, what kinds of utterances they produce and any salient stylistic features of these utterances. We then consider how the voices are represented linguistically, that is, how Henry uses language in his narrative to provide his own account of the lived experience of voice-hearing. We point out several distinctive patterns in the way Henry introduces the voices, namely: the use of Direct Speech as opposed to other forms of speech presentation, the use of the verbs of perception hear and feel and the use of 'non-factive' expressions ${ }^{9}$ that qualify the reality status that Henry attributes to the voices, such as the expression $I$ thought. We finish with some concluding remarks on the implications of our approach for an understanding of Henry's individual experience and, more generally, for the assessment and appreciation of first-person accounts of voice-hearing in clinical practice. Our approach differs from earlier typologies of voice-hearing in that our claims are based on a detailed analysis of the voice-hearer's own narrative, rather than on responses to interview questions about the person's voice-hearing experiences. ${ }^{10}$

\section{BACKGROUND: SCHIZOPHRENIA, NARRATIVE AND HD}

Mental illness, and especially psychosis, still carries considerable stigma. Schizophrenia, in particular, 
tends to be poorly understood, ${ }^{2} 3$ and sufferers are often feared as dangerous and violent. It is, therefore, important to increase understanding of an illness that, as Patrick Cockburn himself explains, is in fact more likely to harm those who have it than

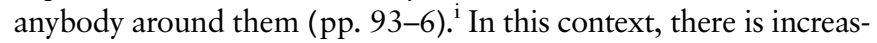
ing recognition of the value of narratives (both fictional and nonfictional) in enhancing understanding and empathy on the part of healthcare professionals, the families of sufferers and the general public. ${ }^{11-14}$ Books such as HD, Saks's The Center Cannot Hold: My Journey Through Madness ${ }^{15}$ and Filer's The Shock of the Fall ${ }^{16}$ have been praised for giving readers a very strong sense of the 'lived experience'17 of the symptoms associated with a diagnosis of schizophrenia.

HD is an example of a relatively new genre of cowritten autobiographies that are narrated from the alternating perspectives of individuals involved in the events being described. Of 17 chapters, Henry narrates five and a half, his mother Jan Montefiore contributes entries from her journal to one, and Patrick narrates the remaining chapters. The multivoicedness of the book gives us a first-person account both of what it is like to live with a close family member's psychotic episodes and to suffer from schizophrenia or rather to have the kinds of experiences that lead to that diagnosis (since Henry is minimally ambivalent about this). In Patrick's (and Jan's) narratives we also see an attempt to give a third-person account of Henry's experiences. While we recognise the role of memory, subjectivity and performance in writing about oneself, ${ }^{18}$ we describe Henry's and Patrick's narratives, in particular, as autobiographical on the basis of a relationship of identity among author, narrator and protagonist in each case. ${ }^{19}$

The book begins with Henry's first psychotic episode and traces his and his family's experience through some rather traumatic times, corresponding to several psychotic attacks, diagnosis, various hospitalisations and escapes from mental institutions, different degrees of resistance and acceptance on Henry's part, setbacks and then, arguably, a certain amount of progress towards the end.

Henry's sections of the book are unusual among autobiographical narratives of schizophrenia in their temporal proximity to the most severe phase of his psychosis. In a BBC radio interview (February 2011), Patrick describes writing the book as Henry's 'main achievement over the last 3 years' and highlights the fact that the book was written before Henry could be described as 'well'. In the preface to the book, he also comments that this made Henry ideally placed to write from the inside about what it was like to have an acute mental illness in which trees and bushes spoke and voices called him to flee into the night or plunge into icy water where he might drown' (p. xiii). Indeed, this exceptional inside view has greatly contributed to the book's success, both in terms of readership and of recognition from mental health researchers and professionals. In January 2013, HD was the third most popular book on schizophrenia, and the most popular autobiography on schizophrenia, on Amazon.co.uk. Unusually for an autobiography, it has been reviewed in several medical journals: the Lancet, Psychosis, The American Journal of Psychiatry and the British Journal of Psychiatry. Most lay and expert reviewers comment on the vividness with which events are described and on how much the book has enabled readers to empathise with Henry.

${ }^{\mathrm{i}}$ All page references are to: Cockburn and Cockburn. ${ }^{1}$
Indeed, Henry's narrative style is striking for what Patrick describes as 'a radiant simplicity and truthfulness about his actions' (p. xv) as in the extract below:

I found myself walking on a road parallel to the train tracks. I felt I was going on a mission. You know fire hydrants are yellow and have an $\mathrm{H}$ on them. I thought the $\mathrm{H}$ stood for Henry. I climbed a barbed-wire fence and sat under a big tree. I put down all the stuff I had amassed: bits of metal, bits of wood, and a big bag of clay. I felt the tree telling me to take off my shoes. I was scared, as I had been arrested previously for not wearing shoes. I climbed over another barbed-wire fence and found myself in the undergrowth beside the railway track. A train went past and I was in full view. I found my way under the root of a tree and could feel it talking to me in my head. (pp. 39-40)

Before turning to our analysis of Henry's narrative, we provide a brief overview of AVHs and their connection with schizophrenia.

\section{AUDITORY VERBAL HALLUCINATIONS AND SCHIZOPHRENIA}

Voice-hearing is a broad and relatively common phenomenon. Although it is associated with a number of conditions in addition to schizophrenia, ${ }^{20}$ it does not necessarily constitute a symptom of a mental disorder. Approximately 15\% of 'mentally healthy' individuals report voice-hearing experiences. ${ }^{21} \quad 22$ Moreover, hearing the voice of gods, ancestors and/or spirits is a normal and generally accepted part of many religious experiences. $^{2}$

In the context of schizophrenia, it has been noted that hallucinatory voices might be threatening or menacing; they might give a running commentary on the person's behaviour or thoughts and two or more voices might converse with each other. ${ }^{7}$ AVHs are most commonly 'narrated' in second or third person but may also be purely descriptive and non-personal. AVHs may sometimes be positive, but more often involve commands, personal insults and abuse. ${ }^{8} 10$ On average, people diagnosed with schizophrenia report hearing three different voices and sometimes interact with their voices in a kind of dialogue. $^{8} 10$ The voices might be identifiable and be attributed to individuals actually known to the person or to him/herself. However, the source of the voice may also be unknown. ${ }^{8}{ }^{10}$ In these cases, voices are sometimes attributed to external entities, who are often perceived to have the purpose to harm the person hearing them. Around $72 \%$ of diagnosed patients interpret their voices as forces of good or evil, conspiracy or plot and believe them to be ghosts, spirits or aliens. ${ }^{23}$ An influential clinical explanation for voice-hearing in schizophrenia links it with a 'failure of metarepresentation,' that is, a failure to correctly attribute the source of a proposition that the person entertains, thus mistaking one's own thoughts or inner speech for an external event. ${ }^{102425}$

Despite their importance in the diagnosis of schizophrenia and other disorders, the specific content of AVHs has tended to be seen simply as a symptom, rather than taken into consideration as part of an individual's experience. ${ }^{22}$ Moreover, no systematic attention has been paid to the linguistic choices that people make when narrating their experiences of voice-hearing and the potential significance of these choices. As we show below, different ways of reporting AVHs might indicate differences in how people experience them, which in turn might have implications for the nature and severity of their condition and the impact that these voices have on their lives. In a piece on 'visual broadcast' in schizophrenia, Hunter et $a l^{4}$ stress the 
diagnostic importance of paying close attention to 'patients' verbatim accounts of their psychiatric symptoms', as 'disorders of the mind can produce diverse and, perhaps, patient-specific symptoms whose essence can only be captured by patients' own descriptions of their experiences'. In the rest of this paper, we show how a close linguistic analysis of Henry's accounts of AVHs can lead to insights into the distinctive characteristics of his experiences. While we recognise that, as a published autobiography, Henry's chapters in HD may have undergone an editing process, we assume that they closely reflect his own language use, especially given the emphasis Patrick puts on presenting Henry's 'firsthand testimony' (p. xiv).

\section{A TYPOLOGY OF HENRY'S VOICES}

Among the reasons why Henry was diagnosed with schizophrenia, and subsequently sectioned, was the fact that he heard voices that were regarded as hallucinatory and that he was a danger to himself as a result of following the orders given by some of these voices. For example, he repeatedly executed the order to take off his clothes and run away, which brought him close to death by hypothermia on more than one occasion. In this section, we provide a typology of the voices Henry reports as a starting point for the more detailed linguistic analysis presented in the next section. We discuss what source the voices are attributed to, the speech acts they perform and the distinctive stylistic features of some of the utterances attributed to them.

In his own chapters, Henry reports hearing voices that others cannot hear 49 times. He attributes these voices varyingly to plants, animals, inanimate things (eg, his shoes or the wind) or people in his life who are not talking to him at the time when Henry hears them. Sometimes Henry also hears unattributed, disembodied voices and on two occasions he reports his own internal voice (In my head, I had been calling my friend Keeva a "nigga", p. 169). Table 1 shows whose voice Henry hears and how often he reports hearing them.

Interestingly, in just under $45 \%$ of occurrences, Henry describes hearing the voices of plants, especially trees and brambles: for example, It [a tree] told me to come to London. (p. 125) and There is a tree I sit under in the garden in Lewisham which speaks to me and gives me hope (p. 222). To the best of our knowledge, hearing the voices of plants is not commonly reported in the clinical literature on schizophrenia: people diagnosed with the illness tend to report hearing human voices. ${ }^{10}$ In addition, Henry's narrative suggests that he likes being surrounded by plants and nature.

Henry's voices mostly fall into the non-dialogic secondperson category (where this is possible to ascertain from his narration): the voices address Henry using the second-person pronoun you, and there are only two occasions where he

Table 1 Henry's voices: sources

\begin{tabular}{lc}
\hline Who speaks? & How often? \\
\hline Plants & 22 \\
People Henry knows in real life & 7 \\
Disembodied/unattributed voices & 7 \\
Inanimate things & 6 \\
Animals & 4 \\
Henry's own voice & 2 \\
Supernatural beings & 1 \\
Total & 49 \\
\hline
\end{tabular}

reports being in a dialogue with the voices, both involving plants. The voices generally tell Henry to act or not act in a particular way, ${ }^{8}$ and in such commands or orders, the second person is implied. Table 2 shows the main types of speech acts performed by the different kinds of entities that Henry presents as sources of what we regard as hallucinatory voices. The notion of 'speech act' originated in J.L. Austin's work within 20th century philosophy of language ${ }^{26}$ and captures the idea that, by producing utterances, we perform different kinds of actions, such as promising, commanding, thanking and so on. In the case of Henry's AVHs, 69\% of speech acts can be identified as commands, as in:

1. I thought the leaves of ivy brushing against my skin were telling me to pull down my trousers. (p. 89)

2. I heard a voice telling me to go into a house and steal something (p. 193)

3. I felt brambles, trees, and wild animals all urging me on (p. 31)

4. I heard my friend Phil's voice saying, "No, Henry, don't do that." (p. 42)

5. "Never lie, Henry," [the trees] replied. (p. 87)

By and large, however, the voices Henry reports do not make negative comments. Only three out of 39 instances are pejorative or critical in some way and only one of these is actually critical of Henry himself (I believed that some ghost in the cottage I was reading [a book] in was trying to tell me I was mad, p. 36). The other critical voices make negative comments about people that Henry knows. In this sense Henry's experience of voicehearing is in contrast with the tendencies reported in the literature on schizophrenia, where threatening voices appear to be a significant part of the experience of AVHs, especially voices that threaten or criticise the hearer. ${ }^{27}$

A further interesting aspect of the voices Henry hears is that on three occasions (two plants and one disembodied voice), they speak to him in rhyme, as in:

6. [the thornbush] said what the tree had said earlier-that I should go to London. It said I should go to Hackney, where they "don't go to school half the time, because all they do is rhyme." (p. 125)

7. The tree talked to me in a sort of Shakespearian rhyme: You must not act the knave When others rant and rave. (p. 121)

Henry is a visual artist studying at art school at the time of his first psychotic episode. As his condition develops, he starts becoming interested in rap, composing and singing his own songs. He also becomes particularly attuned to rhythms and patterns in his environment more generally. The appearance of rhyming voices in his AVHs could indicate a connection between what is happening in his life more broadly (his own interests and activities) and the voices that he hears. A similar link between the content of AVHs and prior experience, knowledge and expectations has already been noted. ${ }^{28}$ Such a link, if it was established more broadly, might provide further support for the 'failure of metarepresentation' theory of schizophrenia. ${ }^{24}$ However, to the best of our knowledge, there is no reference in the literature to cases where the linguistic style of AVHs directly mimics such personal factors. 
Table 2 Henry's voices: speech acts

\begin{tabular}{|c|c|c|c|c|c|}
\hline Who speaks? & Commands & $\begin{array}{l}\text { How } \\
\text { often? }\end{array}$ & Other speech acts & $\begin{array}{l}\text { How } \\
\text { often? }\end{array}$ & Totals \\
\hline Plants & $\begin{array}{l}\text { To go somewhere, take clothes off, not do } \\
\text { something }\end{array}$ & 14 & $\begin{array}{l}\text { Praise, encouragement, general } \\
\text { statement }\end{array}$ & 6 & 20 \\
\hline People Henry knows in real life & To go somewhere, not do something & 3 & Request for information, consolation & 2 & 5 \\
\hline $\begin{array}{l}\text { Disembodied/unattributed } \\
\text { voices }\end{array}$ & $\begin{array}{l}\text { To go somewhere, not do something, take clothes } \\
\text { off }\end{array}$ & 4 & & & 4 \\
\hline Inanimate things & To go somewhere, not to go somewhere & 3 & & & 3 \\
\hline Animals & To go somewhere & 3 & Encouragement & 1 & 4 \\
\hline Henry's own voice & & & Insult, general statement & 2 & 2 \\
\hline Supernatural beings & & & Criticism & 1 & 1 \\
\hline Totals & & 27 & & 13 & $39 *$ \\
\hline
\end{tabular}

\section{LINGUISTIC REPORTING OF HENRY'S VOICES}

In this section, we turn to some distinctive patterns in Henry's representation of hallucinatory voices and reflect on their implications for his individual subjective experience of these voices. First, we consider Henry's use of Direct Speech as opposed to non-direct forms of speech presentation. ${ }^{29}$ We then consider some distinctive patterns in Henry's choice of words when introducing hallucinatory voices, and particularly the sensory verbs hear and feel, and various kinds of non-factive expressions, that is, expressions that reduce the strength of the truth claim made by an utterance. ${ }^{9}$

Within stylistics and narratology, a crucial aspect of the linguistic representation of spoken utterances is whether they are reported directly ("Never lie, Henry," they replied, p. 87) or indirectly (It said I should go to Hackney, p. 125). ${ }^{29}$ Semino and Short's typology ${ }^{30}$ includes four non-direct modes of speech presentation, three of which are employed by Henry to represent AVHs, that is, Indirect Speech, Narrator's Representation of Speech Acts and Narrator's Representation of Voice (see table 3 for examples). Here, we are concerned particularly with the contrast between the choice of Direct Speech as opposed to any of the non-direct categories.

Direct Speech reporting is conventionally associated with a verbatim representation of what was said, and hence with a higher degree of faithfulness to the original utterance than is the case for the non-direct modes of presentation. ${ }^{29}$ This is in spite of the fact that verbatim reproductions are not realistically possible, or even aimed for, in many narrative contexts. In a systematic quantitative study, Semino and Short ${ }^{30}$ found that Direct Speech normally accounts for approximately 50\% of instances of speech presentation in written narratives, including relatively

Table 3 Henry's voices: types of speech presentation

\begin{tabular}{lcl}
\hline Speech presentation categories & Occurrences & $\begin{array}{l}\text { Per cent out of all } \\
\text { occurrences }\end{array}$ \\
\hline $\begin{array}{l}\text { Direct Speech } \\
\text { Indirect Speech }\end{array}$ & 7 & 14 \\
$\begin{array}{l}\text { Narrator's representation of speech act } \\
\text { (eg, 'My father's voice consoled me') }\end{array}$ & 13 & 41 \\
$\begin{array}{l}\text { Narrator's representation of voice } \\
\text { (eg, my shoes were talking to me) }\end{array}$ & 9 & 27 \\
Total & 49 & 18 \\
\hline
\end{tabular}

personal autobiographical writing such as Henry's. This is likely to be due to the greater effects of vividness and dramatisation of Direct Speech as opposed to the non-direct modes of speech presentation.

As can be seen from table 3 , of the 49 instances of reports of hallucinatory voices in Henry's narrative, only seven are in Direct Speech, amounting to $14 \%$ of the total (eg, I remember the brambles saying, "We are the gods.", p. 87). More specifically, Henry's use of Direct Speech is limited to some instances of the presentation of the voices of people he knows, plants and inanimate forces. In contrast, the voices of animals and supernatural beings, Henry's own voice and unidentified voices are always introduced by means of non-direct forms of speech presentation. However, the numbers of instances involved in each case are not large enough for us to make strong claims about correlations between speech presentation categories and types of voices.

It could be argued that the lower than average overall frequency of Direct Speech in Henry's reports of AVHs is simply a characteristic of his narrative style. However, an analysis of a 3000-word sample from Henry's narrative revealed that, when Henry reports voices that can also be heard by others, he uses Direct Speech reporting in approximately $40 \%$ of the cases (eg, One of the doctors said, "I have some good news for you.", p. 32). This is broadly consistent with average frequencies of direct speech reporting in the study of Semino and Short. ${ }^{30}$ The discrepancy in Henry's reporting of real versus hallucinatory voices may, therefore, suggest that he experiences the latter as qualitatively different and particularly that he may not always perceive them as fully articulated verbal utterances that can potentially be reproduced word for word.

Another indication of the distinctiveness of Henry's experience of hallucinatory voices is his use of verbs of perception and cognition to introduce them. On eight occasions, the verb hear precedes a reference to speech in reports of AVHs, as in:

8. I heard two birds call to me to run away, but I didn't have the stomach to do it. (p. 176)

9. I went into the kitchen and could hear the girl in my head saying, "What do you want? I don't love you." (p. 170)

In these examples, Henry could in principle report the voices that he hears without using an auditory verb (eg, 'two birds called me to run away'). The use of hear in speech presentation generally is technically redundant, so that its presence tends to indicate some peculiarity in the person's perception of a 
particular utterance, for example, that the speaker was not visible before their voice was heard, as in: 'Are you lost?' She heard someone say behind her, from the Oxford English Corpus. In examples such as (8) and (9), the use of hear seems to suggest a heightened degree of awareness of Henry's own sensory processes and foregrounds the subjectivity of Henry's perception of voices. This potentially weakens the reality status that Henry claims for these particular voice-hearing experiences. In example (9), the subjectivity of the perception is also indicated by the phrase 'in my head'.

A more strikingly distinctive pattern in Henry's reports of AVHs is his use of the verb feel in examples such as the following:

10. I felt the tree telling me to take off my shoes. (p. 39)

11. I could feel it [the root of a tree] talking to me in my head. (p. 39)

12. I felt a call from the natural world to run away [...]. (p. 217)

In all of these cases, the sensory verb for touch is used to represent something that would normally be an auditory sensation. This combination, which occurs seven times for AVHs but never for 'real' voices, may be taken as evidence that Henry's experience of hallucinatory voices defies the prototypical distinctions between the senses. More specifically, it could be suggested that Henry experiences 'soundless voices' where something is communicated to the hearer but not through the verbal means that result in an auditory sensation. ${ }^{8} 1031$ In other words, Henry's perception of hallucinatory voices seems to involve the blurring of the boundary between hearing and feeling, so that the vocabulary of English seems inadequate to express the precise nature of his experiences. It is also worth mentioning that the verb feel is only used for the voices of plants and the wind, but, as before, the number of instances is not large enough to claim that we have identified a correlation.

A further way in which Henry's subjectivity is foregrounded in some reports of AVHs is by means of 'non-factive' expressions, ${ }^{9} 32$ that is, various ways of indicating uncertainty about the reality status of the state of affairs being presented:

13. It was at the Priory that I first regularly heard voices from people, rather than from trees and bushes. It was as if I could hear what they were thinking, as if I could hear their thoughts. (p. 42)

14. I thought the leaves of ivy brushing against my skin were telling me to pull down my trousers. (p. 89)

In (13), the use of as if clearly reduces the truth claim that Henry makes about the status of the experience. In (14), I thought can also be seen as a marker of uncertainty, although it is not clear whether Henry doubts his interpretation of what the leaves were telling him or whether or not they were speaking at all.

While, on several occasions, Henry rejects his diagnosis and other people's dismissal of his voice-hearing, approximately $50 \%$ of the AVHs he reports are mediated through his consciousness as in the examples above. As we have shown, such mediation may involve the verbs of perception feel and hear, the verb of cognition think and other non-factive expressions such as as if, or, in other extracts, the verb seem. In all these cases, the occurrence of the various voices is presented by Henry as dependent on his own subjectivity, rather than as a 'fact' about the world he shares with others. This tendency can be explained in different ways. On the one hand, Henry may simply be signalling that these experiences are private and not perceptible by those around him, but nonetheless real. On the other hand, he could be conceding that the voices are not real at all. Indeed, in the course of the narrative, Henry alternates between different attitudes towards his diagnosis and its causes. On some occasions, he acknowledges that something is wrong with him; on other occasions, he claims that his experiences are the result of a 'spiritual awakening' that other people have not had, so that their perceptions are more limited than his own. In addition, the low frequency of Direct Speech and the repeated use of the verb feel to introduce the voices may indicate that Henry does not always experience them as straightforward verbal stimuli. ${ }^{8} 10$

\section{CONCLUDING REMARKS}

In this paper, we have provided a typology of the hallucinatory voices that Henry Cockburn reports in his own chapters in HD and analysed the ways in which he represents them linguistically. Our approach leads to findings that can contribute to a better understanding of the phenomenological characteristics of what are known as 'AVHs' and may have implications for the process of diagnosis.

The general characteristics of Henry's voices do not always appear to correspond to the prototypical description of AVHs as a symptom of schizophrenia. ${ }^{8}$ Henry's voices are often attributed to entities that he is fond of, including particularly plants. When they speak in rhyme, the voices also reflect Henry's own developing interests and behaviours in creative verbal expression. These phenomena are, to the best of our knowledge, undocumented in the literature on schizophrenia. The threat that the voices pose to Henry lies in the consequences of obeying some of their orders, but the voices do not frighten him and they do not undermine his self-esteem. All of these may have implications for the severity and/or precise nature of Henry's psychosis.

The variation we have noticed in the strength of the truth claims Henry makes when reporting AVHs is consistent with his more general ambivalence towards his diagnosis and may also be relevant to an assessment of his condition and to how it might be approached. The low frequency of Direct Speech reporting of AVHs, and the use of verbs of perception and cognition to introduce them, arguably suggests a phenomenological contrast between Henry's experience of 'real' and hallucinatory voices. More specifically, the rarity of Direct Speech and the use of feel suggest that he may not always be describing a straightforwardly auditory perception of a verbal utterance. Rather, at times he appears to have perceived meanings and intentions being communicated to him in a way that transcends the sense of hearing, but that may not be easy to express using the words that English provides for the senses.

The analysis we have conducted potentially opens up promising directions for further investigation. Autobiographical narratives such as Henry's provide a source of evidence for the phenomenology of voice-hearing that can profitably complement the use of other types of data, such as interviews with voice-hearers. Moreover, the detailed linguistic analysis we have demonstrated can provide additional support for the findings of studies that adopt different methods, as well as lead to insights that could not be arrived at in other ways. This applies, for example, to the analysis of the use of sensory and cognitive verbs in the representation of voices and of different forms of speech reporting. A larger-scale application of our approach could lead to meaningful, fine-grained comparisons between the representations of different kinds of voices in the language of individual voice-hearers on the one hand and of different (groups of) voice-hearers on the other. The 
resulting insights into phenomenological differences within the broad phenomenon of voice-hearing can ultimately make a positive contribution to diagnosis and, where appropriate, treatment.

In the context of increasing recognition for the value of engaging with patients on their own terms (eg, the Hearing the Voice project: http://hearingthevoice.org/) and calls to pay close attention to their descriptions of their experiences, ${ }^{4}$ we hope to have demonstrated both the importance of first person, 'expert by experience' narratives already in the public domain, and the potential of linguistic analysis to contribute to a symptom-led approach that prioritises the individual experience over diagnostic categories. ${ }^{2}$

Contributors ZD and ES contributed equally to the planning, conduct (analysis and interpretation) and drafting and reporting of the study described in the article.

Competing interests None.

Provenance and peer review Not commissioned; externally peer reviewed.

\section{REFERENCES}

1 Cockburn P, Cockburn H. Henry's Demons Living with schizophrenia: a father and son story. London: Simon \& Schuster, 2011.

2 Woods A. The voice-hearer. J Ment Health 2013;22:263-70.

3 Woods A. Memoir and the diagnosis of schizophrenia: reflections on the center cannot hold, me, myself, and them, and the 'crumbling twin pillars' of Kraepelinian psychiatry. Mental Health Rev 2011;16:102-6.

4 Hunter MD, Mysorekar S, Woodruff PWR. Visual broadcast in schizophrenia. Med Humanit 2005:31:55.

5 David AS. The cognitive neuropsychiatry of auditory verbal hallucinations: an overview. Cognit Neuropsychiatry 2004;9:107-23.

6 Sommer IE, Daalman K, Rietkerk T, et al. Healthy individuals with auditory verbal hallucinations; who are they? Psychiatric assessments of a selected sample of 103 subjects. Schizophr Bull 2010;36:633-41.

7 American Psychiatric Association. Diagnostic and statistical manual of mental disorders. 5th edn. Washington, DC, 2013.

8 Larøi F, Sommer IE, Blom JD, et al. The characteristic features of auditory verbal hallucinations in clinical and nonclinical groups: state-of-the-art overview and future directions. Schizophr Bull 2012;38:724-33.

9 Kiparsky P, Kiparsky C. Fact. In: Bierwisch M, Heidolph KE, eds. Progress in linguistics. The Hague: Mouton, 1970:143-73.

10 Leudar I, Thomas P, McNally D, et al. What voices can do with words: pragmatics of verbal hallucinations. Psychol Med 1997;27:885-98.

11 Oyebode F. Autobiographical narrative and psychiatry. In: Oyebode F, ed. Mindreading: literature and psychiatry. London: The Royal College of Psychiatrists, 2009:42-54.
12 Flynn D. Narratives of melancholy: a humanities approach to depression. Med Humanit 2010:36:36-9.

13 Kaptein AA, Koopman JJ, Weinman JA, et al. 'Why, why did you have me treated?': the psychotic experience in a literary narrative. Med Humanit 2011;37:123-26.

14 Hamm JA, Leonhardt BL, Fogley RL, et al. Literature as an exploration of the phenomenology of schizophrenia: disorder and recovery in Denis Johnson's Jesus' Son. Med Humanit 2014:40:84-9.

15 Saks E. The center cannot hold: my journey through madness. London: Virago, 2007.

16 Filer N. The shock of the fall. London: The Borough Press, 2013.

17 van Manen M. Researching lived experience: human science for an action sensitive pedagogy. London, Ontario: Althouse, 1997.

18 Smith S, Watson J, eds. Reading autobiography: a guide for interpreting life narratives, 2nd edn. Minneapolis: University of Minnesota Press, 2010.

19 Lejeune P. The autobiographical pact. In: Eakin PJ, ed. On autobiography. Minneapolis: University of Minnesota Press, 1989:3-30.

20 Sacks O. Hallucinations. Basingstoke and Oxford: Pan Macmillan, 2012.

21 Beavan V, Read J, Cartwright C. The prevalence of voicehearers in the general population: a literature review. J Ment Health 2011; 20:281-92.

22 Intervoice. Hearing voices: Essential facts, 2012. http://www.intervoiceonline.org/ about-intervoice/patsy-hague-co-founder (accessed 26 Aug 2014).

23 Fowler D, Freeman D, Steel C, et al. The catastrophic interaction hypothesis: how do stress, trauma, emotion and information processing abnormalities lead to psychosis? In: Larkin W, Morrison AP, eds. Trauma and Psychosis. Hove, England: Routledge, 2006:101-24.

24 Frith CD. The Cognitive Neuropsychology of Schizophrenia. Hove, UK: Lawrence Erlbaum Associates, 1992.

25 Johns L, Gregg L, Allen P, et al. Impaired verbal self-monitoring in psychosis: effects of state, trait and diagnosis. Psychol Med 2006;36:465-74.

26 Austin JL. How to Do Things with Words, 2nd edn., Sbisà M, Urmson J0., eds. Oxford: Oxford University Press, 1975.

27 Honig A, Romme M, Ensink BJ, et al. Auditory hallucinations: a comparison between patients and nonpatients. J Nerv Ment Dis 1998; 186:646-51.

28 Waters F, Allen P, Aleman A, et al. Auditory hallucinations in schizophrenia and nonschizophrenia populations: a review and integrated model of cognitive mechanisms. Schizophr Bull 2012;38:683-92.

29 Leech GN, Short MH. Style in fiction. London: Longman, 1981.

30 Semino E, Short M. Corpus stylistics: speech, writing and thought presentation in a corpus of English writing. London: Routledge, 2004.

31 Jones SR. Do we need multiple models of auditory verbal hallucinations? Examining the phenomenological fit of cognitive and neurological models. Schizophr Bull 2010;36:566-75.

32 Culpeper J, Haugh M. Pragmatics and the English Language. Basingstoke: Palgrave Macmillan, 2014 